\title{
Benzene Contamination in Heat-Treated Carrot Products Including Baby Foods
}

\author{
Dirk W. Lachenmeier", Natalie Steinbrenner, Sigrid Löbell-Behrends, Helmut Reusch and \\ Thomas Kuballa
}

Chemisches und Veterinäruntersuchungsamt (CVUA) Karlsruhe, D-76187 Karlsruhe, Germany

\begin{abstract}
Food products containing carrots were analyzed for benzene contamination using headspace gas chromatography with mass spectrometric detection. Of 82 commercial samples, $88 \%$ contained benzene above the detection limit of $0.04 \mu \mathrm{g} / \mathrm{kg}$. Canned and jarred carrots contained $0.2 \mu \mathrm{g} / \mathrm{kg}$ of benzene on average. Higher levels were found in jarred baby foods containing carrots $(0.9 \mu \mathrm{g} / \mathrm{kg}$ on average). The highest concentrations were found in carrot juices specifically intended for infants $(2.0 \mu \mathrm{g} / 1$ on average). In contrast, freshly home-prepared carrot juices $(n=8)$ and baby foods $(\mathrm{n}=30)$ were all benzene-free. The detection of the human carcinogen benzene at $\mu \mathrm{g} / \mathrm{kg}$ levels in canned foods, jarred baby food and juices containing carrots proves that the level of exposure to benzene through food products is currently underestimated. The potential of this substance to pose a cancer hazard for consumers should be evaluated. Further research into the occurrence of benzene in food products, including formation mechanisms and mitigation measures, is necessary.
\end{abstract}

Keywords: Benzene, food contamination, carrots, baby food, cancer risk.

\section{INTRODUCTION}

Benzene is one of the food contaminants with the highest level of evidence for carcinogenicity [1], and has been classified as carcinogenic to humans (Group 1) by the International Agency for Research on Cancer, a decision based on epidemiological knowledge from occupational exposure, which is causally related to the occurrence of acute non-lymphocytic leukemia [2]. Active as well as passive smoking, automobile exhaust, and driving or riding in automobiles are believed to be the most important pathways for non-occupational benzene exposure [3].

Since high levels of benzene metabolites are frequently reported in children and non-smoking workers without occupational exposure, it was hypothesized that there may be significant sources of benzene that have hitherto been unidentified [4]. One of these sources might be a food product, as benzene was detected not only in certain beverages and soft drinks but also in baby food, specifically in carrot juices intended for infants. These juices contain higher concentrations of benzene than any other beverage group, with an average content above the European Union drinking water limit of $1 \mu \mathrm{g} / 1$ [5]. As there might be a link between certain compounds in carrots acting as precursors for aromatic hydrocarbon formation during the heating process (e.g., carotenoids, terpenes or amino acids [6,7]), we have analyzed a wider range of commercial carrot-derived products and also include freshly home-cooked foods for comparison.

*Address correspondence to this author at the Chemisches und Veterinäruntersuchungsamt (CVUA) Karlsruhe, Weissenburger Strasse 3, D-76187 Karlsruhe, Germany; Tel: 49-721-926-5434; Fax: 49-721-9265539; E-mail: Lachenmeier@web.de

\section{MATERIALS AND METHODS}

Local authorities did the sampling at food manufacturers or retail shops. The samples were randomly selected and collected by government food inspectors. The samples were collected between January and August 2009.

The analysis of benzene was done using static headspace (HS) sampling in combination with gas chromatography and mass spectrometry (GC/MS). For canned foods, we analyzed both the brine and the carrots without the drippings (homogenized by crushing with a fork). Baby foods and juices were analyzed as provided. Ten $\mathrm{ml}$ or $\mathrm{g}$ of each sample was placed in a $20 \mathrm{ml}$ headspace vial. After adjustment with potassium hydroxide solution $(10 \%, \mathrm{~m} / \mathrm{m})$ to achieve a $\mathrm{pH}$ of 10 , the solution was spiked with $100 \mu 1$ of benzene- $d_{6}$ $(100 \mu \mathrm{g} / \mathrm{l}$ in methanol) for internal standardization. The vials were tightly sealed and homogenized using a vortex mixer.

The HS-GC/MS system used for analysis was an Agilent model 6890 Series Plus gas chromatograph in combination with a CTC Combi PAL autosampler and an Agilent 5973N mass selective detector. Acquisition and analysis of data were performed using standard software supplied by the manufacturer. The samples were incubated in the agitator oven of the autosampler at $50^{\circ} \mathrm{C}$ for $30 \mathrm{~min}$. Next, $1000 \mu \mathrm{L}$ of sample headspace was injected into the GC/MS system using the split injection mode (split ratio 2:1). Substances were separated on a fused silica capillary column (Optima 624, $60 \mathrm{~m} \times 0.25 \mathrm{~mm}$ I.D., film thickness $1.4 \mu \mathrm{m}$ ). Helium with a constant flow rate of $1.0 \mathrm{ml} / \mathrm{min}$ was used as the carrier gas. The temperature program was: $35^{\circ} \mathrm{C}$ hold for 1 $\mathrm{min}, 10^{\circ} \mathrm{C} / \mathrm{min}$ up to $240^{\circ} \mathrm{C}$, hold for $10 \mathrm{~min}$. The temperatures for the injection port, ion source, quadrupole and interface were set at $250^{\circ} \mathrm{C}, 230^{\circ} \mathrm{C}, 150^{\circ} \mathrm{C}$ and $250^{\circ} \mathrm{C}$, respectively. 
To determine retention times and characteristic mass fragments, electron impact mass spectra at $70 \mathrm{eV}$ of the analytes were recorded by total ion monitoring. The retention time was $13.34 \mathrm{~min}$ for benzene and $13.28 \mathrm{~min}$ for benzene- $\mathrm{d}_{6}$. For quantitative analysis, the chosen diagnostic mass fragments were monitored in the selected ionmonitoring mode (benzene: $\mathrm{m} / \mathrm{z} 78$ as target ion and $\mathrm{m} / \mathrm{z} 77$ as qualifier ion; benzene- $\mathrm{d}_{6}: \mathrm{m} / \mathrm{z} 84$ as target ion and $\mathrm{m} / \mathrm{z} 82$ as qualifier ion). For quantification, peak area ratios of the analytes to the internal standard were calculated as a function of the concentration of the substances.

The method was validated using authentic samples, each analyzed seven times [5]. The precision of the method never exceeded $6.6 \%$ (coefficient of variation) and the trueness never exceeded 5.3\% (as compared to spiked concentrations), indicating good assay accuracy. Determined according to the German norm DIN 32645, the limit of detection was $0.04 \mu \mathrm{g} / \mathrm{l}$ or $\mathrm{kg}$ and the limit of quantization was 0.13 $\mu \mathrm{g} / \mathrm{l}$ or $\mathrm{kg}$.

To compare the commercially available foods with freshly prepared foods, we have conducted home preparation experiments. Carrot juices were freshly prepared from carrots using a juice extractor (centrifuge-type, Starmix, Reichenbach, Germany). Baby foods were prepared using standard kitchen equipment, e.g. a kitchen stove and a household blender. In general, we cooked the ingredients (carrots, potato and carrot mixtures) in boiling water until done, and then the ingredients were blended, with addition of water to adjust the consistency to correspond with that of typical commercial baby foods. No other additives were used.

\section{RESULTS AND DISCUSSION}

\section{Content of Benzene in Heat-Treated Food Products}

The established HS-GC/MS methodology was able to detect benzene in all kinds of food samples with high specificity and sensitivity down to lower than $1 \mu \mathrm{g} / \mathrm{kg}$ (Fig. 1). Our results show that a very high percentage of the analyzed commercial products $(88 \%)$ were positive for benzene (Table 1). Benzene was detected in canned and jarred carrots in concentrations ranging between $0.1 \mu \mathrm{g} / \mathrm{kg}$ and $0.42 \mu \mathrm{g} / \mathrm{kg}$, while the brine contained slightly higher concentrations between 0.21 and $1.07 \mu \mathrm{g} / \mathrm{l}$. During the heating and storage of preserved foods, benzene apparently diffuses from the food matrix into the surrounding liquid. The exact mechanism for the heat-induced formation of benzene from food constituents is currently unclear. Model experiments by our group have shown that possible precursors with capacity to form benzene include commonly occurring substances such as $\beta$-carotene and phenylalanine, or flavoring compounds such as pinene, limonene and carene [7]. From past experience with alcohol-free beverages it is known that benzoic acid (especially in combination with ascorbic acid) is a potent benzene precursor, however, benzoic acid was not contained in any of our analyzed products, so that we can exclude this formation pathway.

Carrots are an important ingredient in baby foods in Europe and are also used to varying degrees in vegetable- or meat-based infant meals. Jarred carrot-derived baby foods contained benzene in the range of 0.35 to $1.33 \mu \mathrm{g} / \mathrm{kg}$, while the occurrence of benzene in other kinds of baby foods was lower. We focused on food products containing carrots; thus,

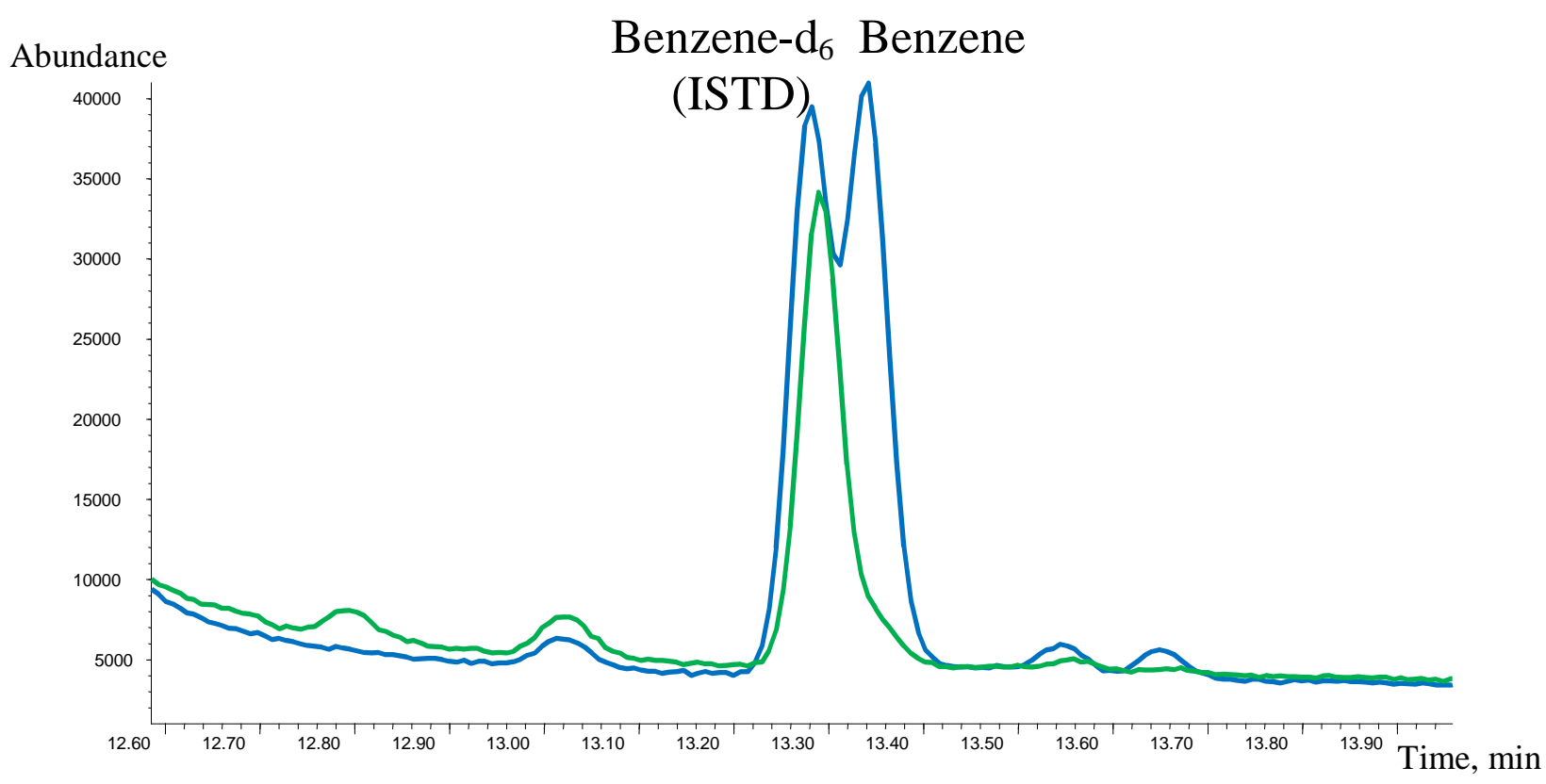

Fig. (1). HS-GC/MS total ion current chromatograms showing a commercial vegetable baby food sample containing $1.4 \mu \mathrm{g} / \mathrm{kg}$ of benzene (blue line) compared to a benzene-free sample of freshly home-prepared carrot baby food (green line). 
Table 1. Occurrence of Benzene in Different Food Products (n.d. $=$ Not Detectable $<0.04 \mu \mathrm{g} / \mathrm{kg}$ )

\begin{tabular}{|c|c|c|c|c|c|c|c|c|c|c|}
\hline Product Category & $\begin{array}{l}\text { Sample } \\
\text { Size }\end{array}$ & $\begin{array}{l}\text { Positive } \\
\text { Samples }\end{array}$ & Mean $^{\mathrm{a}}$ & $\begin{array}{l}\text { Standard } \\
\text { Deviation }\end{array}$ & Median & Minimum & Maximum & $\begin{array}{c}\text { 90th } \\
\text { Percentile }\end{array}$ & $\begin{array}{c}\text { 95th } \\
\text { Percentile }\end{array}$ & $\begin{array}{c}\text { 99th } \\
\text { Percentile }\end{array}$ \\
\hline Carrots in cans - brine $[\mu \mathrm{g} / 1]$ & 8 & $8(100 \%)$ & 0.29 & 0.06 & 0.27 & 0.23 & 0.41 & 0.37 & 0.39 & 0.41 \\
\hline $\begin{array}{c}\text { Carrots in cans - carrots } \\
{[\mu \mathrm{g} / \mathrm{kg}]}\end{array}$ & 8 & $8(100 \%)$ & 0.17 & 0.04 & 0.17 & 0.12 & 0.24 & 0.21 & 0.23 & 0.24 \\
\hline Carrots in jars - brine $[\mu \mathrm{g} / 1]$ & 10 & $10(100 \%)$ & 0.48 & 0.24 & 0.45 & 0.21 & 1.07 & 0.65 & 0.86 & 1.03 \\
\hline $\begin{array}{l}\text { Baby jars with carrots as } \\
\text { major ingredient }[\mu \mathrm{g} / \mathrm{kg}]\end{array}$ & 16 & $16(100 \%)$ & 0.96 & 0.29 & 0.89 & 0.35 & 1.33 & 1.27 & 1.29 & 1.32 \\
\hline $\begin{array}{l}\text { Other jarred baby food with } \\
\text { vegetables (carrot content } \\
\text { unknown) }[\mu \mathrm{g} / \mathrm{kg}]\end{array}$ & 19 & $12(63 \%)$ & 0.34 & 0.36 & 0.32 & 0.00 & 1.36 & 0.70 & 0.84 & 1.26 \\
\hline $\begin{array}{l}\text { Freshly homeprepared carrot } \\
\text { juices }[\mu \mathrm{g} / 1]\end{array}$ & 8 & $0(0 \%)$ & n.d. & - & n.d. & n.d. & n.d. & n.d. & n.d. & n.d. \\
\hline $\begin{array}{c}\text { Freshly homeprepared baby } \\
\text { foods }[\mu \mathrm{g} / \mathrm{kg}]\end{array}$ & 30 & $0(0 \%)$ & n.d. & - & n.d. & n.d. & n.d. & n.d. & n.d. & n.d. \\
\hline
\end{tabular}

${ }^{\mathrm{a}}$ Products below limit of detection were calculated as zero.

we cannot exclude the possibility that other ingredients might also have the potential to produce benzene during heating. However, the results suggest that carrots are the major causative factor.

In pure carrot juices (sold for the general consumer), the average benzene content was $0.52 \mu \mathrm{g} / 1$, while higher concentrations (average $2.01 \mu \mathrm{g} / \mathrm{l}$ ) were detected in pure carrot juices specifically intended for infants. This comparison is interesting as it provides proof for the hypothesis that the benzene produced by carrots is heat-induced [5], as juices for infants are heated longer and at higher temperatures to ensure eradication of spore-forming microorganisms.

None of the freshly home-prepared carrot juices or baby foods contained detectable benzene concentrations. During home cooking, benzene is apparently either not formed at all due to the lower temperature compared to the industrial processes, or it evaporates during the preparation in the open systems (while during industrial preparation it is retained in the closed cans).

\section{Preliminary Risk Assessment}

Based on the assumption that thresholds exist for toxic effects, the U.S. Environmental Protection Agency has established an oral reference dose (RfD) of $4 \mu \mathrm{g} / \mathrm{kg}$ bodyweight/ day for benzene [8]. The RfD is an estimate of a daily exposure to the human population (including sensitive subgroups) that is likely to be without an appreciable risk of deleterious effects during a lifetime. It must be noted that this assessment must be currently treated as preliminary, because the $\mathrm{RfD}$ is based on a non-cancer endpoint (decreased lymphocyte count).
Intake of the food groups shown in Table $\mathbf{1}$ (even in excess) is not likely to exceed the RfD; thus there is no reason to refrain from the occasional use of such foods, however, strengthening the recommendation for consumers to include freshly cooked foods, which are benzene-free, in the diet of their babies.

Furthermore, there remains much uncertainty in assessing human exposure to benzene because the level of benzene contamination in other food groups is virtually unknown. Thus far, benzene exposure from heat-treated vegetables has not been included in risk assessments. As benzene might exist in a wider range of heat-treated foods, they should be included in future surveys aimed at determining people's cumulative benzene exposure. Research into the formation mechanisms of benzene and mitigation measures is needed.

In conclusion, we want to stress that this contribution is preliminary in nature especially regarding sample size and representativeness. Therefore, our results do not allow providing a final risk assessment. However, we hope that our research and especially the finding of benzene in infant foods might stimulate food control groups worldwide to look into this topic, so that hopefully a final toxicological evaluation is possible in the near future.

\section{REFERENCES}

[1] Lachenmeier DW. Carcinogens in Food: Opportunities and Challenges for Regulatory Toxicology. Open Toxicol J 2009; 3: 30-4.

[2] IARC. Benzene. In: IARC Monographs on the Evaluation of Carcinogenic Risks to Humans, Supplement 7. Overall evaluations of carcinogenicity: an updating of IARC Monographs Volumes 1 to 
42. Lyon, France: International Agency for Research on Cancer 1987.

[3] Wallace L. Environmental exposure to benzene: an update. Environ Health Perspect 1996; 104: 1129-36.

[4] Johnson ES, Langård S, Lin YS. A critique of benzene exposure in the general population. Sci Total Environ 2007; 374: 183-98.

[5] Lachenmeier DW, Reusch H, Sproll C, Schoeberl K, Kuballa T. Occurence of benzene as heat-induced contaminant of carrot juice for babies in a general survey of beverages. Food Addit Contam 2008; 25 : 1216-24.
[6] Siems W, Wiswedel I, Salerno C, et al. $\beta$-Carotene breakdown products may impair mitochondrial functions - potential side effects of high-dose $\beta$-carotene supplementation. J Nutr Biochem 2005; 16: 385-97.

[7] Lachenmeier DW, Kuballa T, Reusch H, et al. Benzene in infant carrot juice: Further insight into formation mechanism and risk assessment including consumption data from the DONALD study. Food Chem Toxicol 2010; 48: 291-7.

[8] US EPA. Benzene (CASRN 71-43-2). Integrated Risk Information System. Document 0276. Washington, DC: U.S. Environmental Protection Ageny 2003.

(C) Lachenmeier et al.; Licensee Bentham Open.

This is an open access article licensed under the terms of the Creative Commons Attribution Non-Commercial License (http://creativecommons.org/licenses/by$\mathrm{nc} / 3.0 /$ ), which permits unrestricted, non-commercial use, distribution and reproduction in any medium, provided the work is properly cited. 